\title{
The relationship between urinary tract infection and Vesicourethral reflux in children from eastern galilee region-Israel
}

\author{
Haia Nasser ${ }^{1 *}$, Abo Zaid Said ${ }^{1}$, Susan Nasser ${ }^{1}$, Vigder Fina ${ }^{2}$, Marwan Armaly ${ }^{3}$ and Wael nasser ${ }^{4 *}$ \\ ${ }^{1}$ Department of pediatrics, Baruch Padeh Poriya, Medical Center Lower Galilee, Israel \\ ${ }^{2}$ Department Radiology, Baruch Padeh Poriya, Medical Center Lower Galilee, Israel \\ ${ }^{3}$ Department of Anesthiology, Baruch Padeh Poriya Medical Center, Lower Galilee, Israel \\ ${ }^{4}$ Nephrology \& Hypertension Division, Baruch-Padeh Poriya Medical center, Lower Galilee, Faculty of medicine in Galillee, Bar Ilan University Israel
}

\begin{abstract}
Background: The incidence of vesicoureteral (VUR) in the general population is less than $1 \%$. Reflux carries an increased risk of pyelonephritis and renal failure. The purpose of the current study was to check whether the voiding cystourethrography (VCUG) test is necessary in most cases of upper urinary tract infection (UTI) in children, and to investigate if there is a correlation between the presence of VUR and urinary tract infection, or the reflux is a random finding that does not require monitoring. In the same time, we studied the correlation with various markers of inflammation, renal ultrasound findings (US), $99 \mathrm{~m}$ technetium (Tc)-dimercaptosuccinic acid (DMSA) nuclear renal scans findings, and the clinical presentation.
\end{abstract}

Methods: The current study is retrospective, based on tests taken at the Poriya medical center in Tiberius (Eastern Galilee population), between 2009-2013. The study includes 88 children up to 2 years that were asked for VCUG. All the children had symptoms of UTI. Prior to performing the imaging tests, the children had laboratory tests (blood, urine, culture), then renal US. VCU was performed within two weeks to one month from the beginning of the complaints, for children up to six-month-old. Older children did the voiding test after doing DMSA. DMSA was done 3-5 months after the acute UTI.

Results: Approximately 40\% (37.5 \%) of patients suffered from reflux: 66.7\% with incorrect DMSA (filling defect / scar) had reflux. Only $18.2 \%$ of children with normal DMSA results had reflux. Renal US test was not correlated with VCU results. High inflammation factors levels (CRP, ESR) were found in all subjects with reflux, and only $52.6 \%$ of cases with positive reflux had low lymphocytes levels compared with only $14.3 \%$ in patients without reflux.

Conclusions: VCUG is not required in most cases of upper UTI. Suitable replacement test can be done by renal DMSA, which has also an added value of detecting a potential renal damage (scars). High levels of inflammation factors, erythrocyte sedimentation rate (ESR), and C-reactive protein (CRP) strongly suggest a possible existence of reflux. In contrast, lower levels deny the existence of reflux in children with upper UTI.

\section{Introduction}

Urinary tract infection (UTI) results from bacterial invasion to the urinary tract system. It is one of the most important causes of chronic renal failure. The incidence in boys is about $1 \%$ and $4 \%$ in girls [1,2]. $5-12 \%$ of the children, age between two months to two years with high fever, are suffering from UTI. 20-30 \% of the children will develop another episode, between 6- 12 months after the first episode of UTI [3]. UTI of the upper urinary tract present with fever, flank pain and abdominal pain (Pyelonephritis). Recurrent pyelonephritis can damage the parenchyma with renal scars and arterial hypertension, with subsequently chronic kidney disease (CKD) until end stage renal disease. Vesicoureteral reflux (VUR) is classically considered a risk factor for the development of renal scarring [4-6]. The theory that reflux might produce renal scarring was proposed by Hodson [2]. Ransley and Risdon showed that scarring occurred only when UTI was present in association with VUR and intrarenal reflux [6,7].

Another sub entity of upper tract infection is Nephronia characterized by high fever of $400 \mathrm{C}$ and acute severe inflammation of the renal parenchyma until the formation of abscess. With proper and early diagnosis with CAT scan, intensive and prolonged antibiotic treatment, nephronia is reversible episode. Sometimes the children can have had scars in the upper and lower pole of the kidney $(30-50 \%$ of the cases) [7-9].

VUR results from abnormal backflow of urine from the bladder to the ureteral and in some instance to pelvis and calyx, with incidence of $2 \%$ of the population, with familiar predisposition of $30 \%$ [1-13]. Based on previous studies, the prevalence of VUR is 25 to $40 \%$ in children with UTI [11]. Initially, VUR was graded as mild, moderate, or severe by radionuclide technique (RNC) [12]. Demonstration of tracer reflux in only the ureter by RNC or grade I VUR on VCUG using the International Reflux Study grading system was considered mild. Tracer reflux in a non-dilated renal pelvis on RNC or grade II and III VUR

${ }^{\star}$ Correspondence to: Wael Nasser M.D, Nephrology \& Hypertension Division, Baruch Padeh Poriya medical Center, Lower Galilee, Israel, Email: wnasser@ poria.health.gov.il

Key words: Voiding Cystography, DMSA scan, Renal-UltraSonogaphy, Vesicoureteral Reflux, pyelonephritis, Nephronia

Received: March 10, 2018; Accepted: March 26, 2018; Published: March 28, 2018 
on VCUG was graded moderate. Reflux of tracer into a grossly dilated renal pelvis on RNC or grade IV and V VUR on VCUG was considered severe [12-14]. Cases of bilateral reflux in which the grade differed on each side we reassigned the grade of the more severely affected side. Reflux with grade III, IV and V we have more acute pyelonephritis with renal parenchymal damage and only in $30 \%$ of the cases we can have spontaneous normalization of the reflux. The early detection of VUR allows prophylactic antibiotic treatment or reimplantation of the ureter early, before UTI occurs, and may prevent the development of renal scarring $[15,16]$. The incidence of renal scarring has been reduced from $35 \%-60 \%$ to the current rate of $10 \%-12 \%$ [17]. Identification of VUR in the general population is not feasible, but it would seem sensible to investigate groups at risk by VCUG [17-19] before the first UTI.

Recently, it was published that children with reflux treated with antibiotics, does not shown any superiority on the recurrence of UTIs, scar formations, and kidney function deterioration, suggesting that scars formation are not dependent on the presence or absence of VUR. To mention that $60 \%$ of the renal scars are without VUR. More, the contribution of reflux to the development of scars secondary to UTI was not proven yet, and that reflux is responsible for recurrence of UTIs [11-19]. To prevent serious complications, early diagnosis, proper antibiotic treatment and elimination of risk factors is very important [6-20].

Performance of VCUG is necessary for diagnosis and treatment of VUR. The timing of VCUG performance is controversial. Some authors recommend that VCUG should be done 4-6 weeks after treatment of UTI [10-21]. But others believe that VCUG must be done as soon as possible. After VUS is introduced, the number of VCUG investigations were reduced by over half and, consequently, a significant reduction of radiation exposure in children can be achieved [22-27].

At Baruch-Padeh Poria Medical Center, we are performing all these imaging tests as following: In children with age less than half year, renal US is recommended during admission or nearby. If the ultrasound is abnormal and if there is no response to treatment with antibiotics during $48 \mathrm{hrs}$, VCUG must be performed during the coming two weeks [24-27], and renal scan 3 to 5 months after the UTI [28]. Children with age above half year, ultrasound will be performed first, and renal DMSA scan few months later [26-29]. VCUG will be performed if the scan is abnormal and there is clinical UTIS history. Diagnosis or suspected nephronia, VCUG must be performed. VCUG is the goal standard procedure for the diagnosis of reflux, and renal US be a screening for the existence of reflux in correlation with the hydronephrosis.

The aims of our study were to explore whether there is correlation between the renal scintigrapy results and VUR, whether there is correlation between renal US (Hydronephrosis) and the existence of reflux, and whether there is relationship between inflammatory markers and VUR.

\section{Patients and Methods}

The study is retrospective study, based on tests taken at the Baruch-Padeh Poriya Medical Center in Tiberius (Eastern Galilee population), between: 2009-2013. The study does not include children with congenital anatomical defects. 98 children were recruited for VCUG, but it was performed only in 88 children. The study included children up to age 2 years. All the children suffered from symptoms of UTI and were indication to perform VCUG (UTI, age, recurrent UTIs, resistant to treatment, renal US finding of hydronephrosis, small or ectopic kidney) and clinical pyelonephritis. Children with congenital renal malformation as horseshoe kidney, dysplastic kidney, posterior urethral valve, were excluded. Before entering the VCUG, a urine culture, routine blood tests, renal US and renal DMSA scan, were performed in all children after the acute period (3-5 months). VCUG was performed two weeks to one month from the UTI episode in children aged until 6 monthly, and only after scan in children older than 6 months.

Demographic characteristics includes age, sex, past history, surgery and medications. The children were divided in subgroups according to age: 1-2 yrs, 2-3 yrs, 3-4yrs and 4-5 yrs. Physical examination and pain scale, fever, dysuria, urgency and frequency were recorded. Urine culture, Erythrocyte Sedimentation Rate(ESR), C-Reactive protein (CRP), and total WBC counts, plasma creatinine, urea, bacteria species. Imaging results: Renal US, DMSA scan, and VCUG.

\section{Statistics}

The $\chi 2$ test, the Fisher exact test, the odds ratio (OR), and the Student $\mathrm{t}$-test were used for statistical analysis. All $\mathrm{P}$ values $<0.05$ were considered significant.

\section{Results}

98 children were requested to perform VCUG in our center between the years 2009-2015, and only 88 children performed the test. 33 children had reflux and 55 without reflux. $81.8 \%$ of the 45 of the children without reflux were female, and $87.5 \%$ of the 28 of the children with reflux were female. Mean age of children with reflux were 2.5-3 years. High incidence of reflux was in children less than year of age, and more than 4 years of age. The mean age of children with cystography was 2.7 years in female and 1.2 in male (Figure 1).

Fever was the main complain in almost all children (99\%) with and without reflux, according to VCUG. Disuria and flank pain was absent in more than $90 \%$ of children with and without reflux (Figure 2). $58 \%$ of the children had II-V grade reflux, $42 \%$ had I-II grade reflux (Figure 3).

$37.5 \%$ of patients suffered from reflux. $66.7 \%$ with incorrect mapping (filling defect / scar) had reflux and only $18.2 \%$ of children with normal DMSA scan results had reflux. Renal US test was not correlated with VCUG results. High inflammation factors levels (CRP, ESR) were found in all subjects with reflux, and only $52.6 \%$ of cases with positive reflux had low lymphocytes levels compared only to $14 / 3 \%$ in patients without reflux.

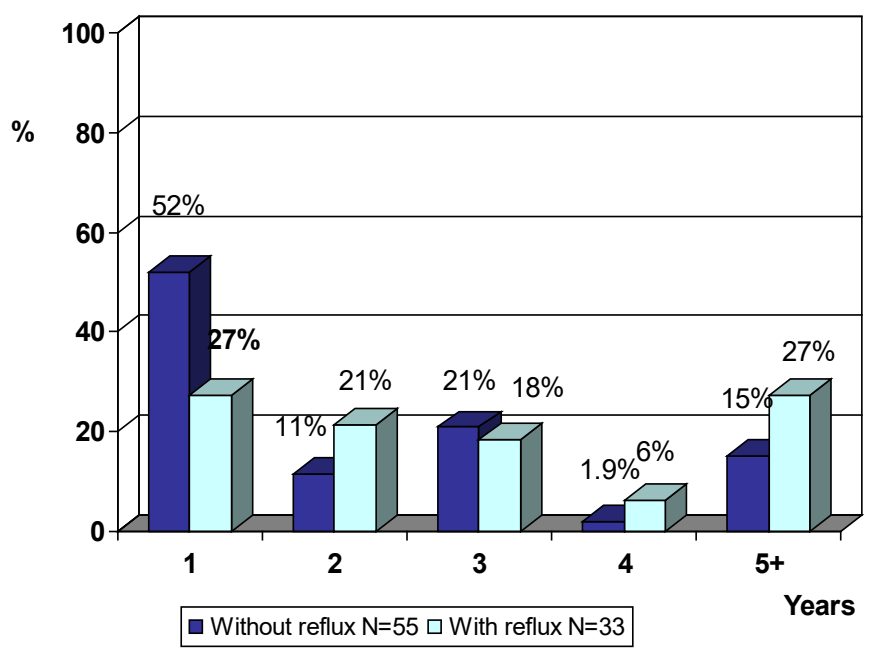

Figure 1. The children age distribution during cystography 


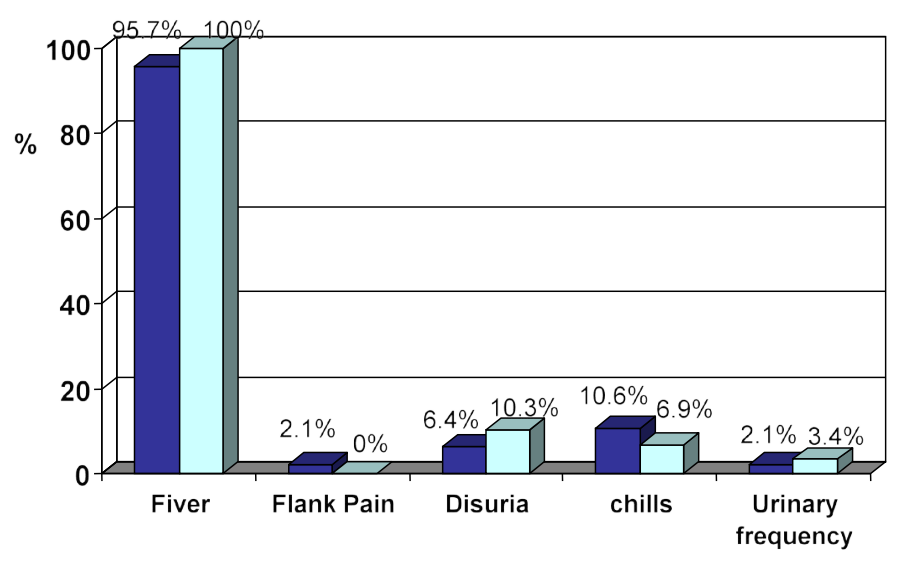

Without reflux $\mathrm{N}=55 \square$ With reflux $\mathrm{N}=33$

Figure 2. Percent of complains during anamesis

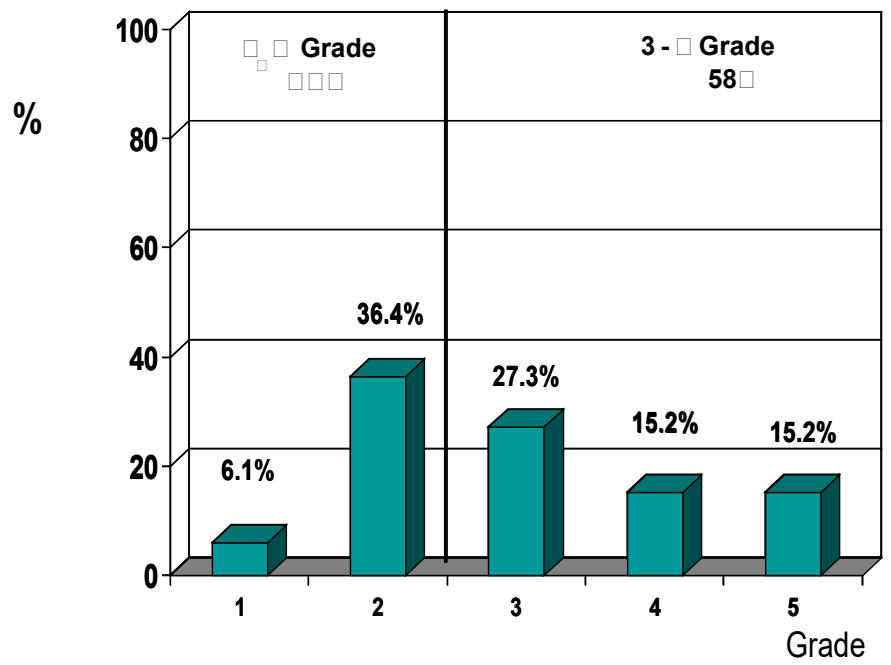

Figure 3. The reflux grade distribution

Inflammatory markers as CRP and ESR were very high in children with reflux. $100 \%$ of children with reflux had high ESR/CRP blood levels, versus $69 \%$ of children without reflux.

Regarding the leukocytes count, leukocytosis (Neutrophils) count was higher in children with reflux but not statistically significant. Impressively, 53\% of children with reflux suffered from lymphopenia versus $14 \%$ of children without reflux $(\mathrm{P}<0.005)$. Kidney function tests were normal in all children with and without reflux. From all children participated in the study, $75 \%$ of children suffered acute pyelonephritis, and $21 \%$ suffered from nephronia (Abscess), and only $38 \%$ of children with nephronia and $36 \%$ with pyelonephritis, were diagnosed with reflux. $20 \%$ of children, urine culture was positive without any relation to the existence of reflux. Escherichia Coli was found as the cause of pyelonephritis in $72 \%$ of children with reflux versus $83 \%$ of children without reflux (Figure 4).

Regarding the role of non-invasive imaging studies in detecting reflux in children with upper urinary tract infection, we found that renal US was the preferred test to perform, because its availability and safety. According to our results, we found that US was not able to diagnose reflux and we don't find correlation between renal US findings (Hydronephrosis) and VCUG results. The same conclusion regarding reflux grade especially grade I-II (Figure 5). Renal scan (DMSA) was performed in all $91 \%$ of children with reflux, and in $80 \%$ it was found abnormal. In $71 \%$ of children without reflux, only $30 \%$ of the scans were abnormal. In all children with reflux, $66.7 \%$ of the scans were abnormal and $18 \%$ were normal $(\mathrm{P}<0.005)$, (Figure 6,7$)$. By the distribution according to reflux grade, we found that in children with low grade reflux (I-II), $66 \%$ of the scans were abnormal and in $89 \%$ of the scans of children with high grade reflux $(\mathrm{P}<0.005)$, (Figure 8 ). Important finding was the correlation between abnormal scans and the

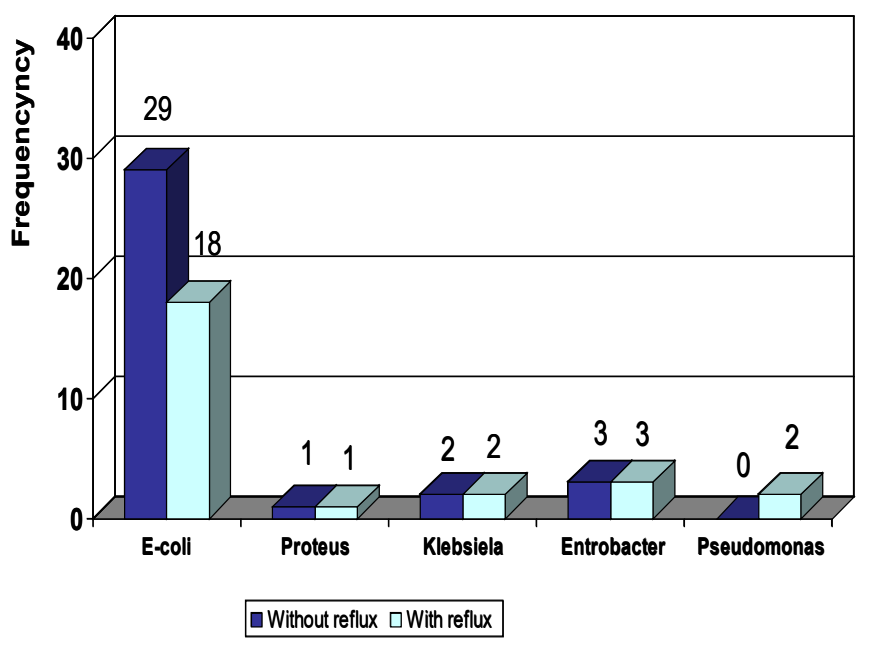

Figure 4. The prevalent frequency of Bacteria species in children with and without reflux

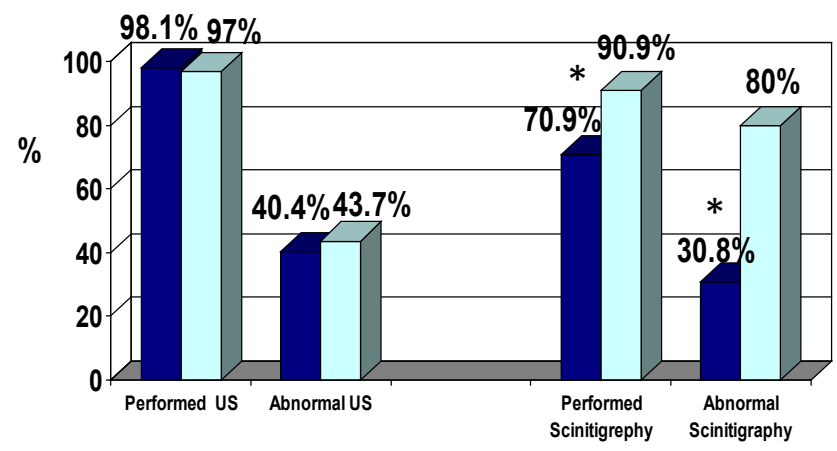

$\mathrm{P}<0.05 \quad \square$ Without reflux $\square$ With reflux

Figure 5. Ultrasound and Scintigraphy scan results in children with \& without reflux

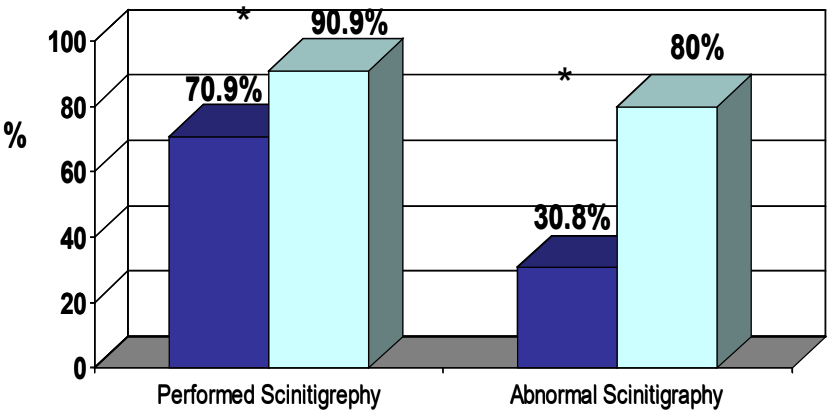

$P<0.05$ $\square$ Without reflux $\square$ With reflux

Figure 6. Schintigraphy Scan results in children with \& without reflux 


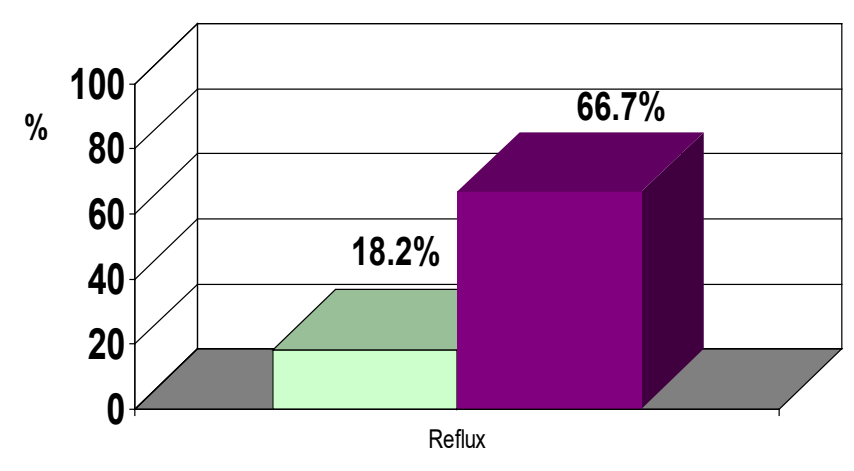

$\mathrm{P}<0.05$

$\square$ Normal Scinitigraphy $\square$ Abnormal Scinitigraphy

Figure 7. Schintigraphy results in children with reflux

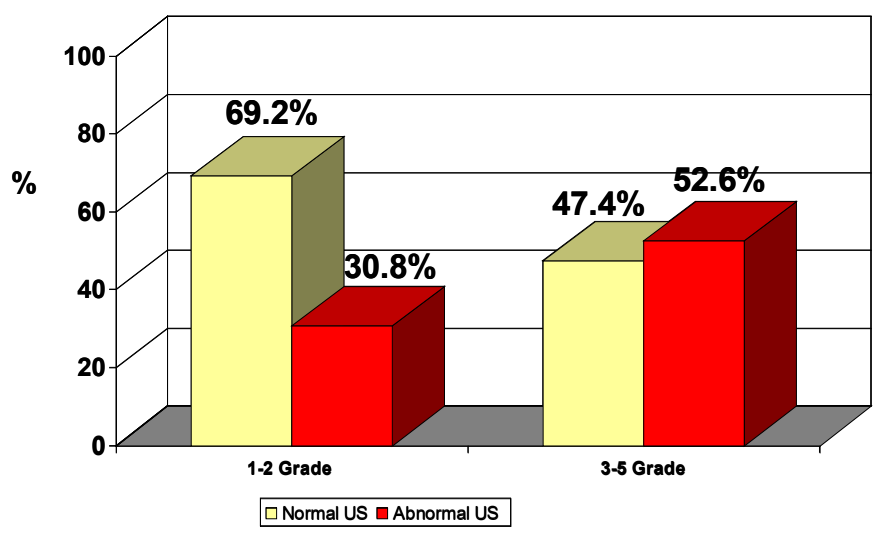

Figure 8. Ultrasound results according to reflux grade

existence of reflux in children age between 1-2 years. Hence, VCUG can predict reflux in most cases and without necessity for VCUG.

\section{Discussion}

Vesicoureteral reflux is the most common anomaly of urinary system. It is one of the most important risk factor of UTI $(1,11)$. VUR is backflow of urine from the bladder to the ureter and in some instance to the pelvis and the calyx [1-4]. The benefits of early detection and treatment of reflux are clear for the prevention of renal damage [30]. Screening for reflux has been recommended in recognized risk groups such as children with UTI. The grade of ultrasound findings was identified as risk factor for VUR. In previous retrospective studies, abnormal renal US findings such as dilatation of the ureter and pelvis were considered as useful for predicting VUR. Other retrospective and prospective studies indicate that renal US is of little benefit in diagnosing VUR [31,32]. There are two types of reflux: primary and secondary. Primary reflux is more common and has familial and hereditary origin, and results from malfunction of ureterovesical valve. Secondary reflux results from increased intravesical pressure due to conditions such as neurogenic bladder or posterior urethral valves (PUV) $[1,20]$.

VCUG is the method of choice for diagnosis of VUR. The timing of VCUG is controversial [23-25]. Many researchers suggest postponing the VCUG until 4-6 weeks after treatment. They believe that acute infection and release of endotoxins lead to transient reflux. Renal US can have performed to rule out hydronephrosis first [26-34].

The current work is based on data from medical records of children in the Eastern Galilee in 88 children with UTI as part of the investigation by UCUG test. In our study we investigate whether cystography is necessary in almost all cases of upper recurrent urinary tract infection in children treated in our center between 2009-2013. Renal DMSA scan was performed in most of the children in the sample before performing the cystography, and only six children aged less than six months have carried out the DMSA scan after the cystography. As expected most patients that suffered from UTI were female ( $84 \%$ female vs $16 \%$ male). Out of total tested, $37.5 \%$ suffered from reflux. In the girls group, $38.4 \%$ suffered from reflex while in boys only $28.6 \%$ were suffer. Clinically, the most frequent symptom in children with upper UTI was fever $(>38 \mathrm{C})$. This finding was positive in all children with reflux. High fever $(>39 \mathrm{C})$ was observed in more than $58 \%$ of children, and in those with reflux, $71 \%$ suffered from high fever (>39C) vs $50 \%$ of children without reflux.

When exploring the laboratory results, CRP and ESR were more positive in children with reflux compared with children without reflux. In the inflammation results in acute phase of infection mapping results issued several months later, we get the best correlation between the results of ESR and DMSA scan. In abnormal scan, we found $100 \%$ increase in ESR value, and normal mapping only in $70 \%$, which is statistically significant $(\mathrm{P}<0.005)$. The correlation between scintigraphy and CRP was low. There was more hydronephrosis by US, and more results of scar and filling defect on scan, and more reflux in VCUG in the left kidney compared to right kidney. Leukocytosis was found in children with UTI and presence or absence of reflux. Lymphopenia was found in children with reflux (52.6\%) and in 14\% without reflux. Blood creatinine and urea were normal in all children.

Renal ultrasound test is the first choice to perform in children with upper urinary tract infection. It's not invasive procedure but there was no correlation between the ultrasound and cystography especially in children with low grade reflux (1\&2).

Regarding the scan test (DMSA) and the comparison with to UVUG, we found that in $91 \%$ of children with reflux, $80 \%$ of renal scan were abnormal. $71 \%$ of the children without reflux, the scan was abnormal in $31 \%(\mathrm{P}<0.005)$. We can summarize that in children with reflux, we found abnormal renal scan in $66.7 \%$, and only $18.2 \%$ were normal.

According to the grade of the reflux: in Reflux 1-2 grade, $66.7 \%$ of scan were abnormal, $33.3 \%$ were normal. In reflux stage III-V, $89 \%$ of the scan were abnormal, and only $11 \%$ were normal. Moreover, in 1-2 years old children, there is a strong correlation between abnormal scan and the presence of reflux. Hence, with non-invasive test as renal scan, we can predict the existence of reflux. But in children with reflux high grade and normal scan (18\%) we need further large study. $75 \%$ of children suffered from pyelonephritis, $21 \%$ suffered from nephronia. It was impressive to find that in $37.5 \%$ of children with nephronia, reflux was diagnosed. In $20 \%$ of children the urine culture was positive without any relation to the existence or absence of reflux. In $72 \%$ of children with reflux, and $82 \%$ without reflux, the pathogenic was Escherichia Coli.

\section{Conclusion}

We can conclude that the existence of reflux in children with UTI/ pyelonephritis is of great relevance, and that VCUG in not indicated in all cases of upper UTIS in children. This finding is confirmed by the strong correlation between the high level of CRP \& ESR, lympopenia, fever duration, sex, and the presence of VUR. Among these variables, the grade of US findings was not of high predictive value for predicting VUR. According to our results, renal scan with DMSA can be the best test to perform for pediatric patients with suspected reflux and URI. 
Positive renal scan results, with high CRP/ESR levels and with grade IV-V US findings by US, and then VCUG is indicated. Early diagnosis and proper antibiotic treatment, can prevent renal parenchyma damage.

\section{Acknowledgement}

The authors would like to thank the patients and their families who cooperated in this study.

\section{References}

1. Jakobsson B, Esbjorner E, Hansson S (1999) Minimum incidence and diagnostic rate of first urinary tract infection. Pediatrics 104: 222-226. [Crossref]

2. Baily R (1979) Vesicoureteral reflux in healthy infants and children. In: Hodson J, Kincad-Smith P (eds) Reflux nephropathy. Mason 59-61.

3. Mohd A, Kaiser A, Khurshid A, Mohd M (2013) Urinary Tract Infection in Children. British Journal of Medicine and Medical Research 4: 21-31.

4. Ditchfield MR, De Campo JF, Cook DJ (1994) Vesicoureteral reflux: an accurate predictor of acute pyelonephritis in childhood urinary tract infection? Radiology 190: 413-415. [Crossref]

5. Sastre JB, Aparicio AR, Cotallo GD, Colomer BF, Hernandez MC (2007) Urinary tract infection in the newborn: clinical and radio imaging studies. PediatrNephrol 22: 17351741. [Crossref]

6. Olbing H, Smellie JM, Jodal U, Lax H (2003) New renal scars in children with severe VUR: a 10-year study of randomized treatment. Pediatr Nephrol 18: 1128-1131. [Crossref]

7. Lin KY, Chiu NT, Chen MJ (2003) Acute pyelonephritis and sequelae of renal scar in pediatric first febrile urinary tract infection. PediatrNephrol 18: 362-365. [Crossref]

8. Lopez PJ, Celis S, Reed F, Zubieta R (2014) Vesicoureteral reflux:current management in children. Curr Urol Rep 15: 447. [Crossref]

9. Gordon I, Barkovics M, Pindoria S, Cole TJ, Woolf AS (2003) Primary vesicoureteric reflux as a predictor of renal damage in children hospitalized with urinary tract infection: a systematic review and meta-analysis. J Am Soc Nephrol 14: 739-744. [Crossref]

10. Belman AB (1997) Vesicoureteral reflux. Pediatr Clin North Am 44: 1171-1190.

11. Williams G, Fletcher JT, Alexander SI, Craig JC (2008) Vesico ureteral reflux. $J$ Am SocNephrol 19: 847-862.

12. Van den Abbeele AD, Treves ST, Lebowitz RL (1987) Vesicoureteral reflux in asymptomatic siblings of patients with known reflux: radionuclide cystography. Pediatrics 79: 147-153.

13. Connolly LP, Treves ST, Zurakowski D, Bauer SB (1996) Natural history of vesicoureteral reflux in siblings. J Urol 156: 1805-1807.

14. Sciagra R, Materassi M, Rossi V (1996) Alternative approaches to the prognostic stratification of mild to moderate primary vesicoureteral reflux in children. J Urol 155: 2052-2056. [Crossref]

15. Report of the International Reflux Study Committee (1981) Medical versus surgica treatment of primary vesicoureteral reflux. Pediatrics 67: 392-400. [Crossref]

16. Zaki M, Badawi M, Al Mutari G, Ramadan D, AdulRahman M (2005) Acute pyelonephritis and renal scarring in Kuwaiti children: A FOLLOW-UP STUDY USING 9999mTc DMSA renal scintigraphy. Pediatr Nephrol 20: 1116-1119.
17. Ataei N, Madani A, Esfahani ST (2004) Screening for vesicoureteral reflux and renal scars in siblings of children with known reflux. Pediatr Nephrol 19: 1127-1131. [Crossref]

18. Coulthard MG (2009) Vesicoureteric reflux is not a benign condition. Pediatr Nephrol 24: 227-232. [Crossref]

19. Straub J, Apfelbeck M, Karl A, Khoder W, Lellig K (2016) Vesico-ureteral reflux Diagnosis and treatment recommendations. Urologe A 55: 27-34. [Crossref]

20. Abolfazl Mahyar, Parviz Ayazi, Saeid Tarlan, Alireza Moshiri, Monadi Hamidfar (2012) When is the Best Time for Voiding Cystourethrogram in Urinary Tract Infection of Children? Acta Medica Iranica 50: 468-472. [Crossref]

21. Piaggio G, Innocenti MLD, Toma P, Calevo MG, Perfumo F (2003) Cystosonography and voiding cystourethrography in the diagnosis of vesicoureteric reflux. Pediatr Nephrol 18: 18-22. [Crossref]

22. Mentzel HJ, Vogt S, John U, Kaiser WA (2002) Voiding urosonography with ultrasonography contrast medium in children. Pediatr Nephrol 17: 272-276. [Crossref]

23. Kim YS, Do SH, Hong CH, Kim MJ, Choi SK (2001) Does every patient with ureteropelvic junction obstruction need voiding cystourethrography? J Urol 165: 2305 7.20. [Crossref]

24. Battelino N, Ključevšek D, Tomažič M, Levart TK (2016) Vesicoureteral refux detection in children: a comparison of the midline-to-orifice distance measurement by ultrasound and voiding urosonography. Pediatr Nephrol [Crossref]

25. Carovac A, Zubovic SV, Carovac M, Pasic IS (2015) Significance of Sonographically Demonstrated Ureteral Dilatation in Evaluation of Vesicoureteral Reflux Verified with Voiding Urosonography in Children with Urinary Tract Infection. Acta Inform Med 23: 268-272. [Crossref]

26. You SK, Kim JC, Park WH, Lee SM, Cho HH (2016) Prediction of High-grade Vesicoureteral Reflux in Children Younger Than 2 Years Using Renal Sonography: A Preliminary Study. J Ultrasound Med [Crossref]

27. Ataei N, Madani A, Habibi R, Khorasani M (2005) Evaluation of acute pyelonephritis with DMSA scans in children presenting after the age of 5 years. PediatrNephrol 20: 1439-1444. [Crossref]

28. Asanuma H, Matsui Z, Satoh H, Asai N, Nukui C (2016) Color Doppler Ultrasonographic Evaluation of the Ureteral Jet Angle to Detect Vesicoureteral Reflux in Children. $J$ UrolJun 195: 1877-1882. [Crossref]

29. Nuutinen M, Uhari M (2001) Recurrence and follow-up after urinary tract infection under the age of 1 year. Pediatr Nephrol 16: 69-72. [Crossref]

30. Moorthy I, Easty M, McHugh K, Ridout D, Biassoni L (2005) The presence of vesico ureteric reflux does not identify a population at risk for renal scarring following a firs urinary tract infection. Arch Dis Child 90: 733-736. [Crossref]

31. Massany EZ, Preece J, Gupta A, Lin SM, Wang MH (2013) Utility of screening ultrasound after first febrile UTI among patients with clinically significant vesicoureteral reflux. Urology 82: 905-909. [Crossref]

32. Hellerstein S (2006) Acute urinary tract infection evaluation and treatment Current Opin Pediatr 18: 134-138. [Crossref]

33. Iodal U, Smellie JM, Lax H, Hoyer PF (2006) Ten-year results of randomized treatment of children with severe vesicoureteral reflux. Final report of the International Reflux Study in Children. Pediatr Nephrol 21: 785-92. [Crossref]

Copyright: (C2018 Nasser H. This is an open-access article distributed under the terms of the Creative Commons Attribution License, which permits unrestricted use, distribution, and reproduction in any medium, provided the original author and source are credited. 